\title{
The Algorithm Improvement of Sealing System Energy Consumption in Side Door Closing Process
}

\author{
Guohua Qiu, a ${ }^{1,}$ Aiquan $\mathrm{Yu}^{1, \mathrm{~b}}$, Shanshan Wang ${ }^{2, \mathrm{c}^{*}}$, Gang Long ${ }^{1, \mathrm{~d}^{*}}$ \\ ${ }^{1}$ No.201 Anyan Rd.Jiading Shanghai P.R.China \\ ${ }^{2}$ No.4800 Caoan Rd.Jiading, Shanghai, China \\ aquguohua@saicmotor.com, byuaiquan@saicmotor.com, \\ cshanshan1509@126.com, 'LongGang@saicmotor.com
}

\begin{abstract}
Keywords: Door closing process, elastic compression resistance force, damping force of seal venting holes, air bind resistance.

Abstract. The mathematical model is established for energy consumption caused by the compression resistance force, damping force of seal venting hole and air bind resistance between two seals during the side swing door closing process. The energy consumption of a certain vehicle's right front door sealing system is calculated by the loop iteration method using VBA language of EXCEL. The results show that total energy consumption of sealing system is $2.78 \mathrm{~J}$ while three parts energy account for $28 \%, 25 \%$ and $47 \%$ respectively. Thus the damping force of seal venting hole and air bind resistance between two seals are important influence factors of seal energy consumption.
\end{abstract}

\section{Introduction}

Sealing system can insulate dust, rain and noise from the environment, thus improving the riding comfort of vehicle. However, the energy consumption caused by sealing system accounts for $30 \%$ to $50 \%$ of the side door closing energy. Too large closing effort of side door will affect passengers' first impression on the car. Door seal is composed of dense rubber and sponge rubber and it's hyper elastic. When the door rotates to a small angle, the seal is compressed and generates compression force. The air flow in the seal bulb and through venting holes will also cause damping force. Furthermore, a seal is installed on the door and the car body respectively. When the door rotates to a small angle, a closed space is formed by two seal, the door and the vehicle body sheet metal parts.

In recent years, there have been a lot of papers researching on the seal energy consumption. Paper 2- 4 researched the seal energy using trial-and-error method. This method requires building a finite element model based on a real door. Then simulation analysis of energy consumption in door closing process is conducted by kinetic analysis software. The door model is re-analyzed and re-modified based on the results. This method not only requires large amounts of manpower, material and long design cycle but also can't be used in initial design guidance. Paper 5 analyzed the seal energy using numerical method. But the compressing direction of every seal point was not taken into account. This paper studies the compression resistance considering the compressing directions, damping force of seal venting hole and the energy consumption caused by air bind resistance between two seals.

\section{Energy Consumption of Seal Compression Resistance}

The sealing strip is divided into $\mathrm{N}$ small segments with the length of $100 \mathrm{~mm}$. The total energy consumption of the seal can be calculated by summing the energy consumption of every segment. Fi is defined as the compression force of one segment. Fi can be obtained through CLD curve according to the amount of compression of the point.

$$
E_{\text {seal }}=\sum F_{i} i_{\text {seali }}
$$

The compression direction of one point on the seal is different from its moving direction and the compression direction of each point on the seal is different. This paper takes each point's compression 
direction into account. The contact angle of a point on the sealing strip is defined as the door angle when the point begins to contact with the body or door. When $\theta<\theta_{c}$, The seal at this point starts to be compressed to produce compression resistance. Fig. 1 shows the deformation schematic diagram of a seal point without sliding. When the door rotates around the hinge, A point on the seal bulb, called seal contact point, contacts with the body at $\mathrm{C}$ point on the vehicle body. Assume the arc $\mathrm{AB}$ is part of the track of $\mathrm{A}$ point rotating around the hinge. If $\mathrm{A}$ point has been in contact with $\mathrm{C}$ point before reaching $\mathrm{B}$ point, the seal bulb will be compressed to produce compression resistance. $\mathrm{CB}$ is the amount of compression of seal at A point.

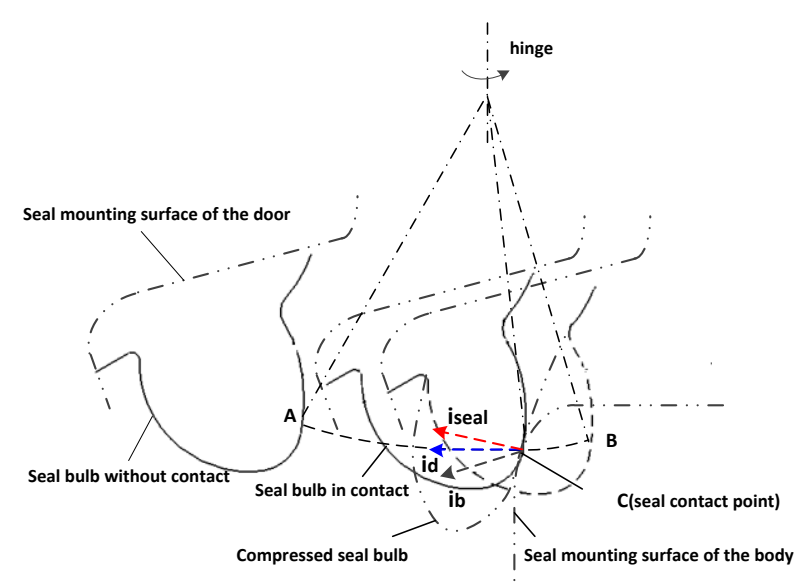

Figure 1 Seal compression schematic

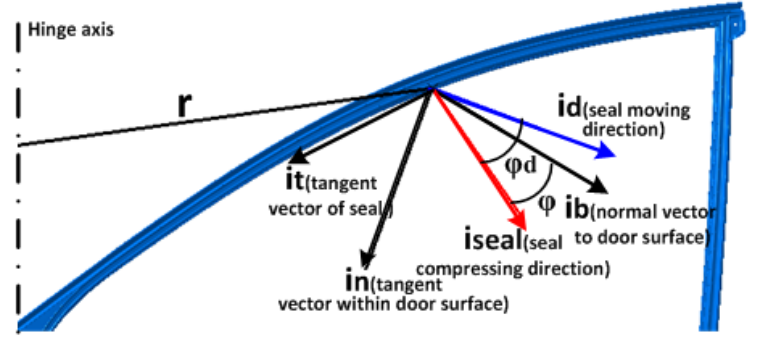

Figure 2 Seal movement schematic

The tangential direction of arc $\mathrm{ABC}$ is the instantaneous moving direction of seal at $\mathrm{i}$ point. $\mathbf{i}_{\mathrm{d}}$ is unit tangent vector of arc $\mathrm{ABC}$,

$$
\mathbf{i}_{d}=\frac{\boldsymbol{l} \times \mathbf{r}}{\|\boldsymbol{l} \times \mathbf{r}\|_{2}}
$$

$l$ is the direction vector of hinge axis, $\mathrm{r}$ is the direction vector of rotating radius of the contact point to the hinge axis, $\mathrm{d}$ is the length of $\operatorname{arc} \mathrm{CB}, d=2 r_{i} \sin (\theta / 2)$, the motion displacement of seal at point i $\mathrm{CB}$ can be written as:

$$
\mathbf{d}=d \cdot \mathbf{i}_{m}
$$

The compression direction of seal is perpendicular to the body panel. Fig. 2 shows that there is an angle $\varphi_{d}$ between the moving direction $i_{d}$ and compressing direction $i_{\text {seal }}$ of seal at one point. The movement distance $d$ is not the amount of compression. The compressing direction $i_{\text {seal }}$ can be determined by the normal vector of door surface $i_{b}$ and the tangent vector of the seal's cross section within the door surface $i_{n}$, as shown in Fig.2. $\varphi$ is the angle between the compressing direction of the seal $i_{\text {seal }}$ and the normal vector of door surface $i b$. The actual amount of compression can be written as:

$$
\mathbf{i}_{\text {seal }}=i_{\text {seal }}\left(\mathbf{i}_{\mathbf{b}} \cos \varphi+\mathbf{i}_{\mathbf{n}} \sin \varphi\right)
$$

$\varphi_{\mathrm{d}}$ can be written as:

$$
\cos \varphi_{d}=\frac{\mathbf{i}_{\mathbf{d}} \cdot \mathbf{i}_{\text {seal }}}{\left|\mathbf{i}_{\mathbf{d}}\right|\left|\mathbf{i}_{\text {seal }}\right|}=\frac{\mathbf{i}_{\mathbf{d}} \cdot\left(\mathbf{i}_{\mathbf{b}} \cos \varphi+\mathbf{i}_{\mathbf{n}} \sin \varphi\right)}{\left|\mathbf{i}_{\mathbf{d}}\right|\left|\mathbf{i}_{\mathbf{b}} \cos \varphi+\mathbf{i}_{\mathbf{n}} \sin \varphi\right|}=\mathbf{i}_{\mathbf{d}} \cdot\left(\mathbf{i}_{\mathbf{b}} \cos \varphi+\mathbf{i}_{\mathbf{n}} \sin \varphi\right)
$$

The energy consumption caused by seal compression resistance is:

$$
i_{\text {seal }}=d_{\text {seal }} \cos \varphi_{d} \quad E_{i}=F_{i} \cdot i_{\text {seali }}
$$




\section{Energy Consumption of Damping Force of Seal Venting Hole}
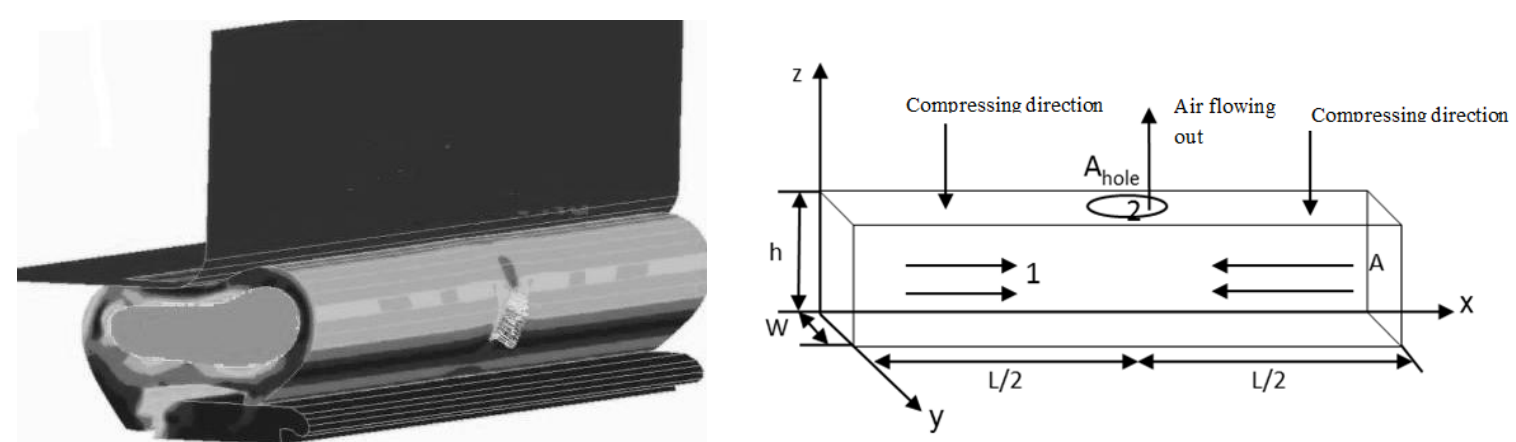

Figure 3 Schematics of the seal with vent hole Figure 4 Simplified model of damping force [5]

Vent holes are generally arranged uniformly on the seal. When the seal bulb is compressed, the air in the bulb flows and flows out through vent holes thus generating damping force [6]. A seal section with one vent hole is regarded as the research object. Fig. 3 is the schematic diagram of seal in compressing condition and Fig. 4 is a simplified model established according to work principle of the damping force when the seal is compressed. Regardless of fluid surface tension, the force applied to the surface of an ideal fluid is only hydrostatic pressure. The damping force of unit length of the seal caused by the gas outflow can be obtained through Lamb-Ge. Eq. 6 .

$$
\begin{aligned}
& \frac{\partial \mathbf{u}}{\partial t}+\nabla\left(\frac{\mathbf{u}^{2}}{2}\right)+2 \boldsymbol{\omega} \times \mathbf{u}=\mathbf{f}-\frac{1}{\rho} \nabla p \\
\mathbf{u}= & {\left[\begin{array}{lll}
u_{x} & u_{y} & u_{z}
\end{array}\right] \boldsymbol{\omega}=\left[\begin{array}{lll}
\omega_{x} & \omega_{y} & \omega_{z}
\end{array}\right] \mathbf{f}=\left[\begin{array}{lll}
f_{x} & f_{y} & f_{z}
\end{array}\right] }
\end{aligned}
$$

Normally, the unit vector along streamline is

$$
d \mathbf{s}=\mathbf{i} d x+\mathbf{j} d y+\mathbf{k} d z
$$

The scalar product of Eq. 6 and Eq. 7 is

$$
\frac{\partial \mathbf{u}}{\partial t} \cdot d \mathbf{s}+d\left(\frac{\mathbf{u}^{2}}{2}-\pi+\int \frac{d p}{\rho}\right)=2(\mathbf{u} \times \boldsymbol{\omega}) \cdot d \mathbf{s}
$$

The air flow in seal bulb can be regarded as irrotational flow, that is $\boldsymbol{\omega}=0$ and $\pi=0$, equation (8) can be written as:

$$
\frac{\partial \mathbf{u}}{\partial t} \cdot d \mathbf{s}+d\left(\frac{\mathbf{u}^{2}}{2}+\int \frac{d p}{\rho}\right)=0
$$

Eq. 9 is integrated along the streamline:

$$
\int \frac{d p}{\rho}+\frac{u^{2}}{2}+\int \frac{\partial}{\partial t} \mathbf{u} \cdot d \mathbf{s}=\text { Constant }
$$

Where $s=L / 2, d s=-d x$, then

$$
p_{e x}-p(x)=\rho\left[\frac{u^{2}(x, t)-u_{e x}^{2}}{2}\right]+\rho\left(\frac{L}{2}-x\right) \frac{d}{d t} u(x, t)
$$


According to Fig. 4, we can obtain these equation:

$$
u_{e x} \& \text { hole }=L(1 \& h+w h) \quad u_{e x}=\frac{L(1 \& h+w h)}{\AA_{\text {hole }}^{\&}}
$$

In a similar way, we can obtain the Eq. 12,

$$
\begin{aligned}
& u(x, t)=-\frac{x}{2}\left[\frac{\text { l\& }^{\&}}{w}+\frac{h^{\&}}{h}\right] \\
& \frac{\partial}{\partial t} u(x, t)=-\left(\frac{1 \&}{w}+\frac{h^{\&}}{h}\right) \cdot \frac{u}{2}+\left(\frac{w^{2}}{w^{2}}+\frac{h^{\&}}{h^{2}}\right) \cdot \frac{x}{2}
\end{aligned}
$$

The total damping force of seal can be written as:

$$
F=2 \int_{0}^{L / 2} w\left[P(x)-P_{e x}\right] d x
$$

The nonlinear damping force of unit length of the seal is:

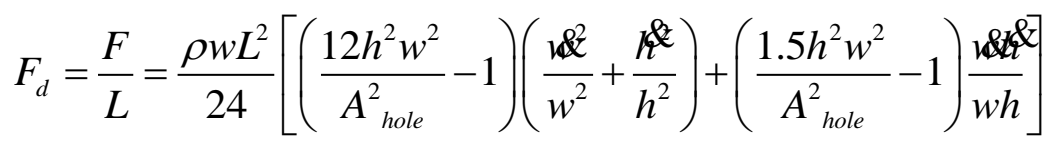

F-nonlinear damping force

L-the length of seal

$\rho$ - air density

$\mathrm{w}=\mathrm{A} / \mathrm{h}$-the effective width of seal

A-cross-section of seal
$\dot{W}=\frac{\vec{h}\left(\frac{a}{h}-g\right)}{h}-$ effective width change rate

$\grave{h}$-effective height change rate

$\dot{A}$ - cross-section change rate

$\dot{A}_{\text {hole }}$ vent area change rate

\section{Energy Consumption of Air Bind Resistance between Two Seals}

Generally, a seal is installed on the door and the vehicle body respectively. When the door rotates to a small angle, a closed space is formed by the seal, the door and the vehicle body, as shown in Fig. 5 [7]. The door rotates continuously and the air in the space is compressed thus generating closing resistance force. The cross section of closed space is shown in Fig. 5(a)-(d). The closed space is divided into 4 parts, the top side of the door, the latch side of the door, the bottom side of the door and the hinge side of the door, numbered as space 1-4. The closed space can be simplified as a trapezoid cylinder as shown in Fig. 5(e) (f). 


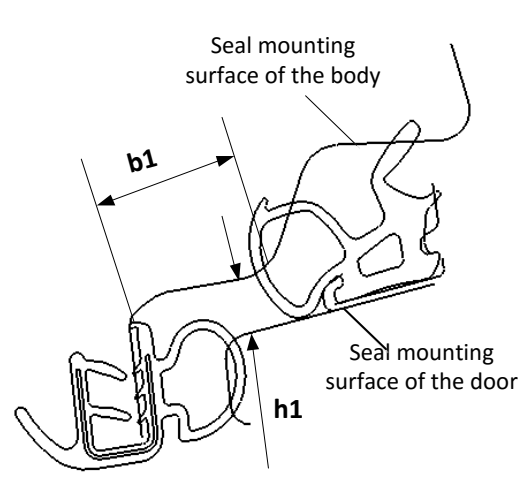

(a) The top side section of door

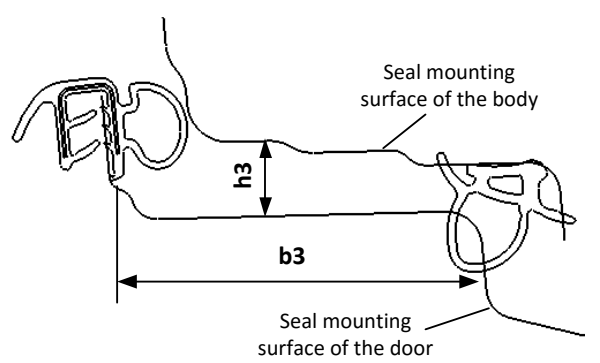

(c) The bottom side section of door

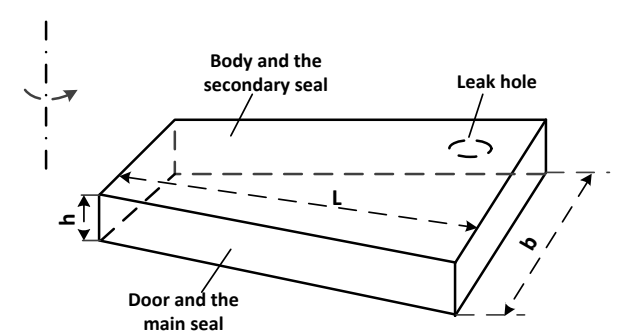

(e) The top and bottom closed space

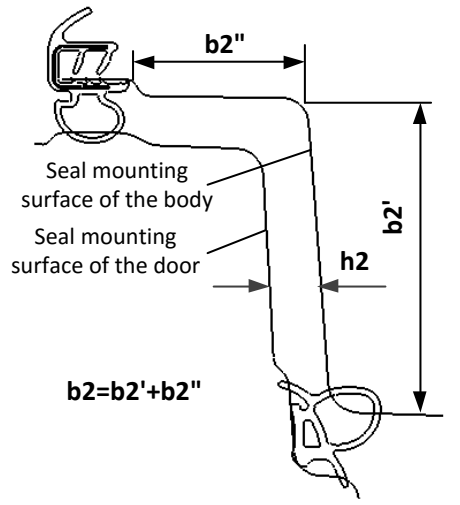

(b) The latch side section of door

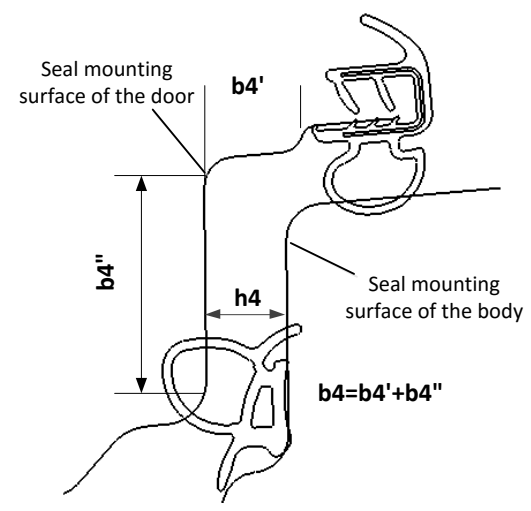

(d) The hinge side section of door

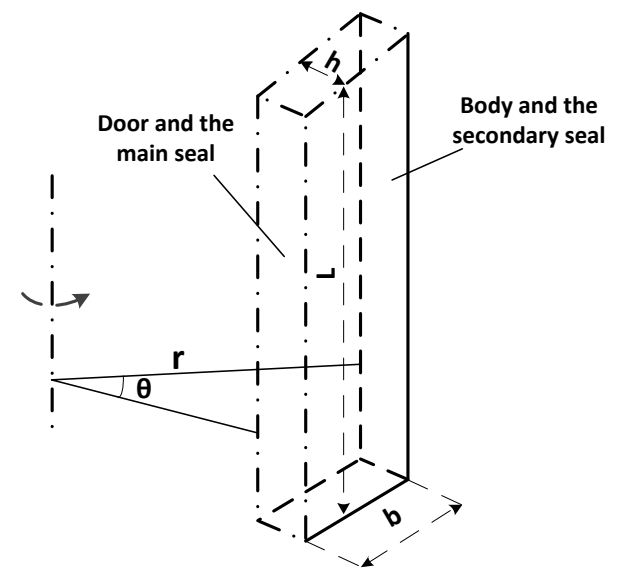

Figure 5 Simplified model of closed space between two seals

As shown in Fig.5, $\mathrm{L}$ represents the length of the space. $\mathrm{h}$ represents the height of the space, that is the distance between the door sheet metal and the body sheet metal. $b$ represents the width of the space, that is the distance between two seals. In the closing process of side swing door, the width $b$ of the space decreases constantly. Because of the inclination of hinge axis, the center of gravity declines constantly and the height $h$ of the closed space changes all the time. As the side swing door closes, the height h of space 1 increases, the height of space 3 decreases constantly. The direction of height of space 2 and 4 is perpendicular to the moving direction of gravity center, so the height h of space 2 and 4 doesn't change. Relief hole represents reserved holes on the door panel. When the seal is not full contacted with the door or vehicle body, there will be leak area between two seals. The leak area is represented by Ae. 
As the side swing door closes, the air in the space is compressed and flowed out from relief holes and leak area [8]. According to the air mass conservation law, a differential equations can be established as follows:

$$
\frac{d(\rho V)}{d t}=-\rho v_{e} A_{e}
$$

Where, $\rho$ is air density, $V$ is the volume of air flowed out, $v_{e}$ is the leak speed of air. $\rho, V$ and $v_{e}$ change constantly as the door closes. Eq. 16 can be written as:

$$
\frac{d \rho}{d t}=-\frac{1}{V} \rho v_{e} A \mathrm{e}-\rho \frac{1}{V} \frac{d V}{d t}
$$

According to Bernoulli's equation:

$$
\frac{1}{2} \rho v_{e}^{2}=P-P_{a}
$$

The leak rate of air can be written as:

$$
V_{e}=\sqrt{\frac{2\left(p-p_{a}\right)}{\rho}}
$$

$\mathrm{P}_{\mathrm{a}}$ represents the atmospheric pressure; $\rho$ is air density in the space; $\mathrm{p}$ is the pressure of the space.

The gas isentropic equation can be written as:

$$
\frac{p}{p_{a}}=\left(\frac{\rho}{\rho_{a}}\right)^{\frac{7}{5}}
$$

Where, $7 / 5$ represents air isentropic coefficient. Differentiated and simplified the Eq. 19 as :

$$
\frac{d p}{d t}=\frac{7}{5} \frac{p_{a}}{\rho_{a}^{\frac{7}{5}}} \rho^{\frac{2}{5}} \frac{d \rho}{d t}
$$

Substitute the Eq. 20 into Eq. 17, we can achive:

$$
\frac{d p}{d t}=\frac{7}{5} \frac{p_{a}}{\rho_{a}^{\frac{7}{5}}} \rho^{\frac{2}{5}}\left(-\frac{\rho}{V} \sqrt{\frac{2\left(p-p_{a}\right)}{\rho_{a}}} A_{e}-\frac{\rho}{V} \frac{d V}{d t}\right)
$$

If $K=\sqrt{\frac{2}{\rho_{a}}}=1.2278 \mathrm{~m}^{3 / 2} / \mathrm{kg}^{1 / 2}$, Eq. 21 can be simplified as:

$$
\frac{d p}{d t}=-\frac{7}{5} \frac{1}{V} \frac{p_{a}}{\rho_{a}^{\frac{7}{5}}} \rho^{\frac{7}{5}} K A_{e} \sqrt{p-p_{a}}-\frac{7}{5} \frac{p_{a}}{\rho_{a}^{\frac{7}{5}}} \rho^{\frac{7}{5}} \frac{1}{V} \frac{d V}{d t}
$$


According to Eq. 19, we can obtain $p=p_{a} \frac{\rho^{\frac{7}{5}}}{\rho^{\frac{7}{5}}}$, and then substitute it into Eq. 22:

$$
\frac{d p}{d t}=-\frac{7}{5} \frac{p}{V} K A_{e} \sqrt{p-p_{a}}-\frac{7}{5} \frac{p}{V} \frac{d V}{d t}
$$

The air bind resistance between the two seals can be written as:

$$
F=\left(p-p_{a}\right) \cdot S=\left(p-p_{a}\right) \cdot L h
$$

The energy consumption of air bind resistance between two seals is:

$$
w=F \cdot \frac{R}{2} \cdot d \theta
$$

\section{The Energy Calculation of Sealing Strip System}

The VBA developments tool, built in Excel, can operate the interface by background program. The interface for energy calculation of sealing strip is shown in Fig. 6. The left side of the interface is data input area, including the coordinates of seal points, CLD curves of sealing strip, the information of vent holes distribution, and the information of closed spaces between two seal strips. The right side of the interface is the calculation results, including the energy curve of each sealing strip and the chart of energy distribution.
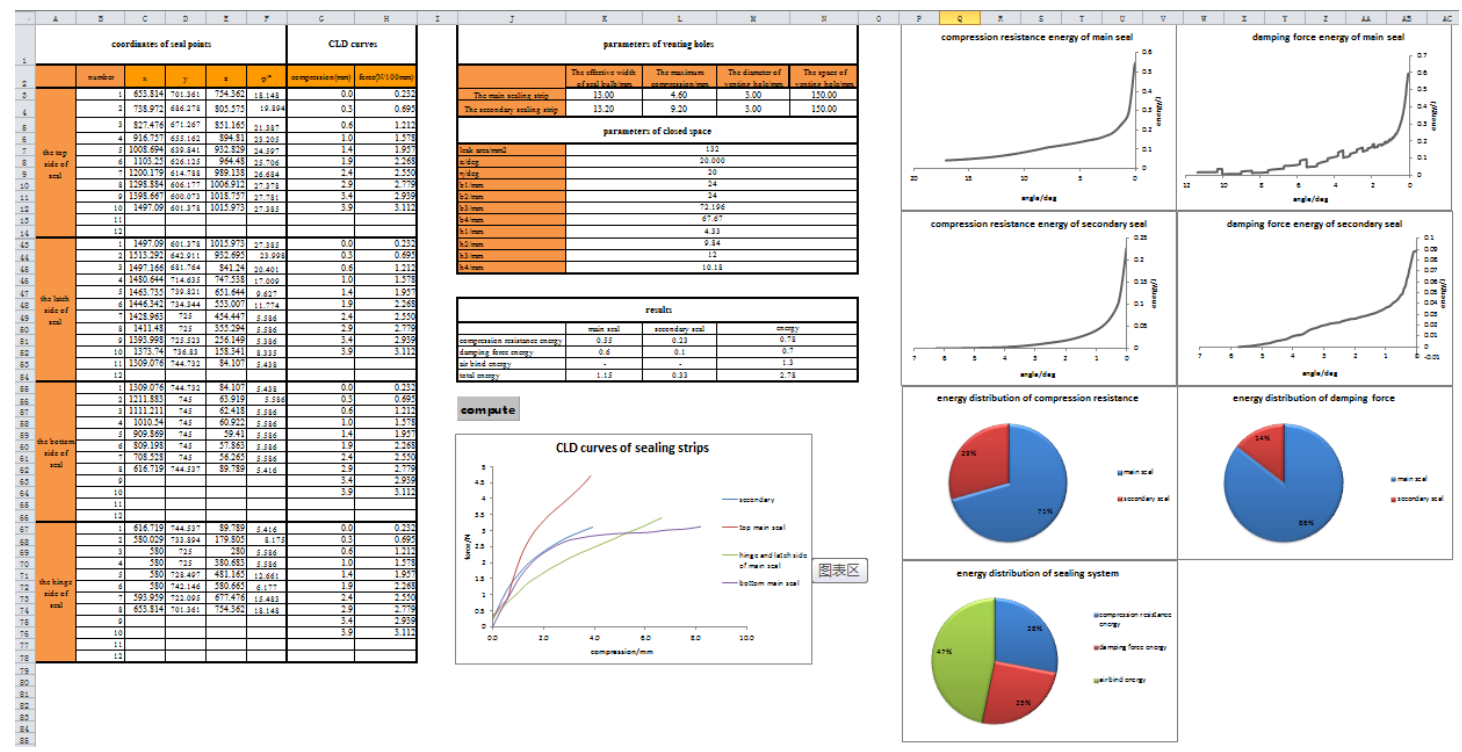

Figure 6 The interface for sealing strip energy calculation

\section{The Calculation for Seal Compression Resistance Energy}

The basic parameters for calculating the seal compression resistance energy, including the mass of the door, barycentric coordinates and the coordinates of seal points as shown in Table 1. The closed space is also divided into 4 parts, the top side of the door, the latch side of the door, the bottom side of the door and the hinge side of the door, numbered as space 1-4. The CLD curves, used for calculating the compression resistance energy of sealing strips, are shown in Fig. 7. 


\begin{tabular}{cccc}
\hline & $\mathrm{X}[\mathrm{mm}]$ & $\mathrm{Y}[\mathrm{mm}]$ & $\mathrm{Z}[\mathrm{mm}]$ \\
\hline Upper hinge & 522.06 & 836.92 & 522.96 \\
\hline Lower hinge & 515.22 & 847.19 & 130.94 \\
\hline Center of gravity & 954.13 & 796.60 & 499.03 \\
\hline
\end{tabular}

Table 1 Basic information of side door

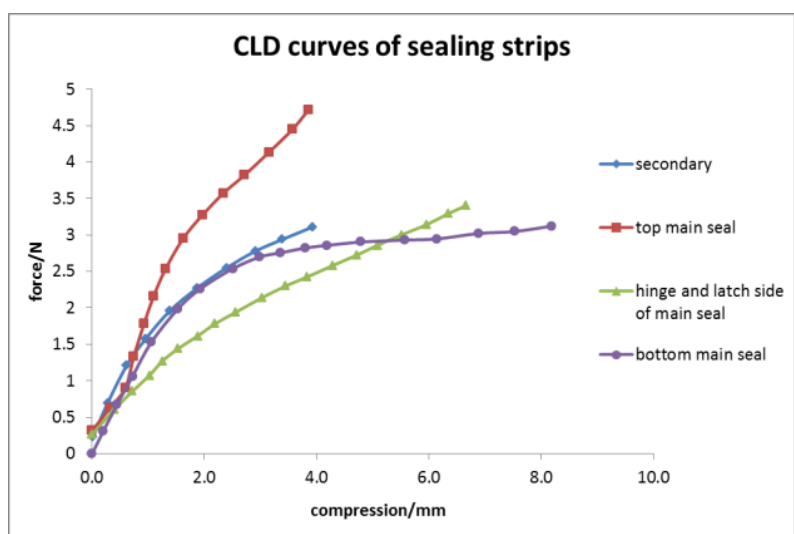

Figure 7 CLD curves of sealing strip

The energy consumption caused by compression resistance of each sealing strip is shown in Fig. 7. It shows that the energy consumption caused by compression resistance of sealing strips nonlinearly increases as the door closes, and the energy consumption increases faster and faster.

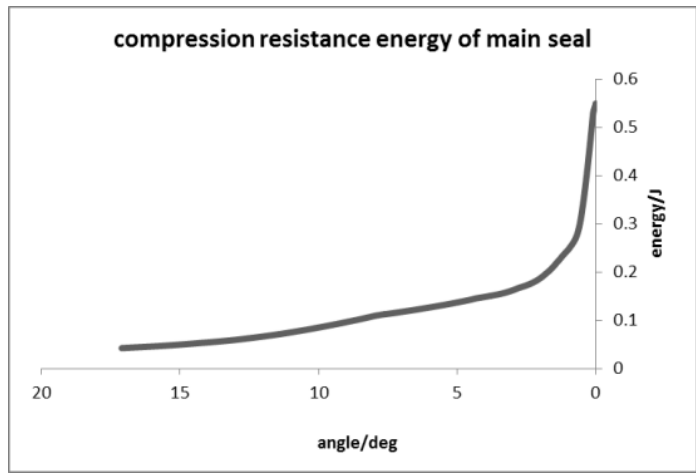

(a)The compression resistance energy of main sealing strip

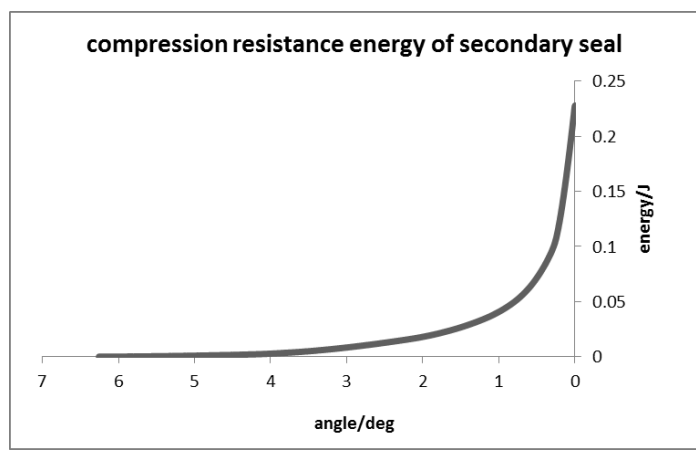

(b)The compression resistance energy of secondary sealing strip

Figure 8 The compression resistance energy of sealing strips

Due to different length, shape and CLD curves of the two sealing strips, the energy consumption caused by compression resistance force of sealing strips is different. As shown in Fig. 10.The compression resistance energy consumption of the main sealing strip accounts for $71 \%$, and that of 
the secondary sealing strip accounts for $29 \%$, that is the sealing strip installed on the door consumes more energy.

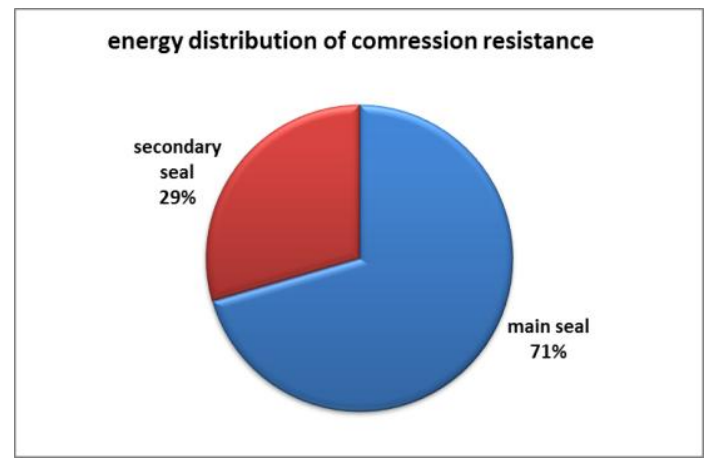

Figure 9 The compression resistance energy ratio of sealing strips

\section{The Calculation for Damping Force Energy of Seal Venting Holes}

Besides the parameters showed in Table 1, the distribution information of venting holes showed in Table 2 is also used for damping force energy calculation. The calculating results of damping force energy are shown in Fig. 10. It shows that the energy consumption caused by damping force of seal venting holes nonlinearly increases as the door closes, and the energy consumption increases faster and faster.

\begin{tabular}{c|c|c}
\hline & The main sealing strip & The secondary sealing strip \\
\hline The effective width of seal bulb[mm] & 13.6 & 13.2 \\
\hline The maximum compression $[\mathrm{mm}]$ & 4.6 & 9.2 \\
\hline The diameter of venting hole $[\mathrm{mm}]$ & 3.0 & 3.0 \\
\hline The space of venting hole $[\mathrm{mm}]$ & 150 & 150 \\
\hline
\end{tabular}

Table 2 The information of seal venting holes

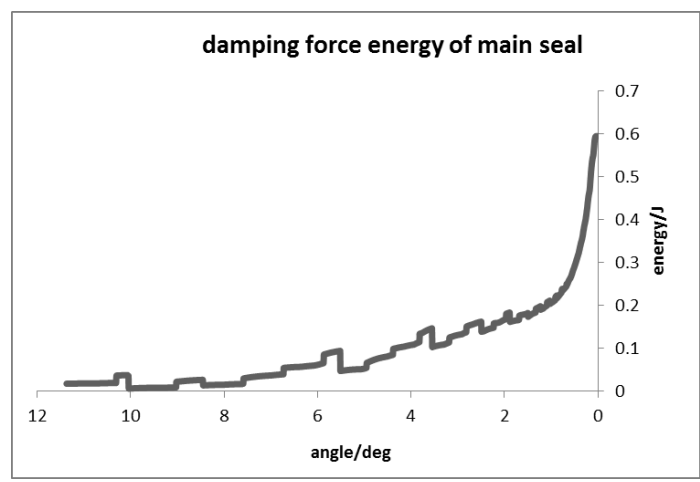

(a) The damping force energy of main sealing strip

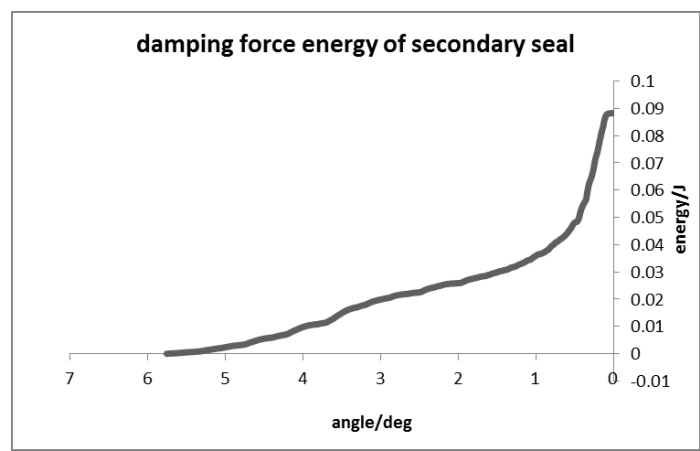

(b) The damping force energy of the secondary sealing strip

Figure 10 The damping force energy of seal venting hole 
Due to different length, shape and compression of the two sealing strips, the energy consumption caused by damping force of seal venting holes is also different. As shown in Fig. 11.The damping force energy consumption of the main sealing strip accounts for $86 \%$, and that of the secondary sealing strip accounts for $14 \%$, that is the sealing strip installed on the door consumes more energy.

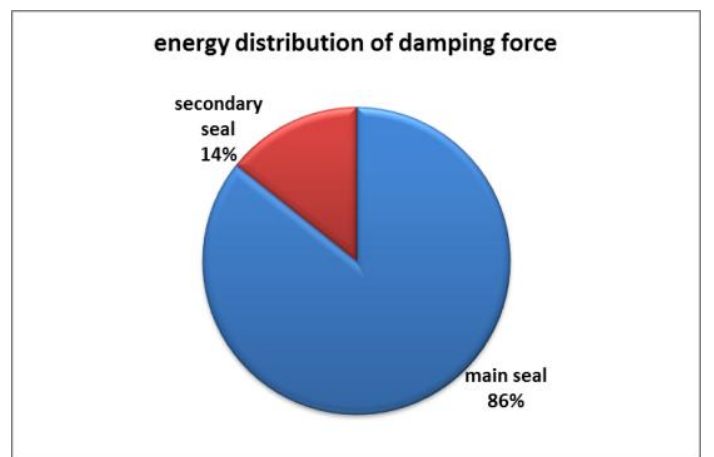

Figure 11 The damping force energy ratio of sealing strips

\section{The Energy Calculation for Air Bind Between Sealing Strips}

The energy calculation for air bind between two sealing strips needs basic parameter of every section of the closed space, such as length, width and height, as shown in Table 3.The energy consumption of air bind between two sealing strips is shown in Fig. 12.

\begin{tabular}{c|c|c|c}
\hline Number of seal section & $1[\mathrm{~mm}]$ & $\mathrm{b}[\mathrm{mm}]$ & $\mathrm{h}[\mathrm{mm}]$ \\
\hline 1 & 1060 & 24 & 4.5 \\
\hline 2 & 1080 & 130 & 13.5 \\
\hline 3 & 1010 & 72 & 12.0 \\
\hline 4 & 735 & 68 & 10.2 \\
\hline
\end{tabular}

Table 3 The parameters of closed space

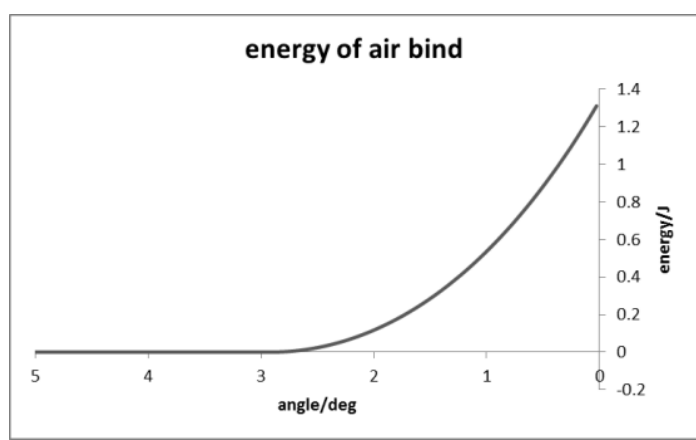

Figure 12 The energy of air bind between two sealing strips

Fig. 13 shows the energy consumption distribution of the compression resistance of sealing strips, the damping force of venting holes and the air bind between two sealing strips. The energy consumption of the whole seal system in the closing process of side door is $2.78 \mathrm{~J}$, while the energy consumption caused by compression resistance accounts for about $28 \%$, the energy consumption caused by damping force of venting holes accounts for about $25 \%$, and the energy consumption caused by air bind between two sealing strips accounts for $47 \%$. 


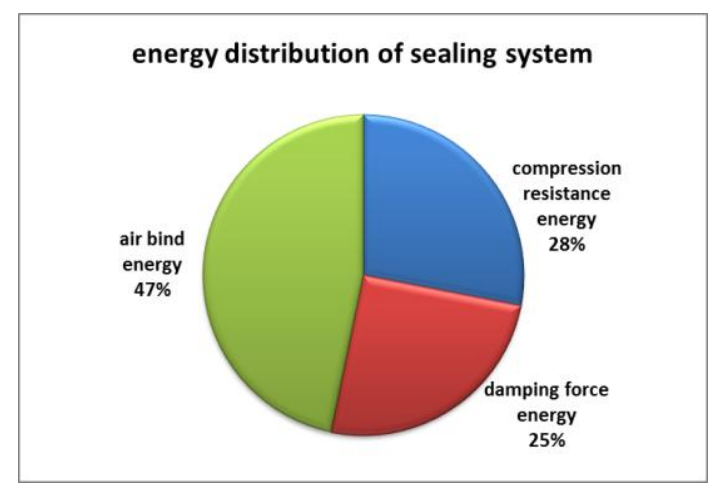

Figure 13 The energy distribution of sealing strip system

\section{Conclusions}

1. This paper analyzed the working principle of compression resistance of sealing strips, damping force of seal venting holes and air bind of the closed space between two sealing strips during side swing door closing process. Simplified geometric models and mathematical models are built to calculate the energy consumption, and a calculation software is developed based on Excel software, can be used to calculate the energy consumption of sealing strip system in different side swing door.

2. Based on a certain kind of vehicle door, the energy consumption caused by seal compression resistance is $0.78 \mathrm{~J}$, the energy consumption caused by venting hole damping force is $0.7 \mathrm{~J}$, and the energy consumption caused by air bind between two sealing strips is $1.3 \mathrm{~J}$. That is the total energy consumption of the seal system is $2.78 \mathrm{~J}$. Compared with the test results, the deviation of calculation result is $8 \%$, the accuracy meets the requirement.

3. Fig. 8 and Fig. 10 show that compared with the sealing strip installed in car body, the energy consumption caused by compression resistance and damping force of sealing strip, which is installed on the door accounts for a large proportion. Fig. 12 shows that for this type of car, the energy consumption caused by seal compression resistance, venting hole damping force and air bind between two sealing strips accounts for $28 \%, 25 \%$, and $47 \%$ respectively. Thus energy consumption caused by air bind between sealing strips has a big effect on the energy consumption of sealing system. It can be improved by processing relief holes on the sheet metal of door or cut off part of door seal strips.

\section{References}

[1] Yunkai G, Ruiyao X, et al. Automotive door seal consumption energy calculation[J]. Journal of Tongji University. 2010, 38(7): 1069-1073.

[2] Qiu P, Qu Y, Wu S, et al. Finite Element Analysis of Door Closing Effort[R]. SAE Technical Paper, 2013.

[3] Zhao J, Zhou C, Zhu X. Analysis of the influence of the seal structure on door closing force for SANTANA[R]. SAE Technical Paper, 2004.

[4] Sandrini V, Massarotti M, Maia M, et al. A case-study about side door closing effort[R]. SAE Technical Paper, 2008.

[5] Yunkai G, Ruiyao X, Lei Y, et al. Development of calculation software for automotive side swing door closing energy [J]. Chinese Journal of Mechanical Engineering, 2010.

[6] Gur Yuksel, Monnan Kenneth N. Modeling the dissipative effect of seal air hole spacing and size on do or closing effort [ J] . Society of Automotive Engineers: 971901, 1997( 5) : 249. 
[7] Karlavage J J, Meernik P R, Pupillo D S, et al. Vehicle door seal venting system and method: U.S. Patent 7,972,204[P]. 2011-7-5.

[8] Morman K N, Wagner D A, Gur Y. Method and system for designing a vehicle door: U.S. Patent 6,081,654[P]. 2000-6-27. 